\title{
The costs and benefits of symmetry in common-ownership allocation problems*
}

\author{
Alexander L. Brown ${ }^{\dagger}$ and Rodrigo A. Velez $z^{\ddagger}$ \\ Department of Economics, Texas A\&M University, College Station, TX 77843
}

September 18, 2014

\begin{abstract}
In experimental partnership dissolution problems with complete information, the divide-and-choose mechanism is significantly superior to the winner's-bid auction. The performance of divide-and-choose is mainly affected by reciprocity issues and not by bounded rationality. The performance of the winner's-bid auction is significantly affected by bounded rationality. Contrary to theoretical predictions divide-and-choose exhibits no first-mover bias.
\end{abstract}

JEL classification: C91, D63, C72.

Keywords: experimental economics; no-envy; divide-and-choose; winner's-bid auction; behavioral mechanism design.

\section{Introduction}

We experimentally study mechanisms for the allocation of an indivisible good among two agents when ownership of the good is symmetric and compensation with an infinitely divisible good, e.g., money, is possible. Examples are a partnership dissolution (Cramton et al., 1987), a divorce settlement (McAfee, 1992), and the allocation of the ball in NFL overtime (Che and Hendershott, 2008). We assume complete information, i.e., agents know each other well-more on this key assumption below. We experimentally compare the performance of two prominent mechanisms: the winner's-bid auction

\footnotetext{
*This paper benefited from audience comments at conference presentations at the 2010 and 2011 North American ESA Meetings, SCW2012, XIII JOLATE, 2013 World ESA Meetings, CRETE2014 and seminar presentations at the University of Alabama, Texas A\&M University, University of California at Santa Barbara, Chapman University, and the University of Sydney. We thank Catherine Eckel and John Van Huyck for comments. We give special thanks to Jacob Williams and Yue Zhang for transcribing survey data from experiments. All errors are our own.

†abrown@econmail.tamu.edu; http://econweb.tamu.edu/abrown

${ }^{\ddagger}$ rvelezca@econmail.tamu.edu; https://sites.google.com/site/rodrigoavelezswebpage/home
} 
(Cramton et al., 1987), a simultaneous move mechanism, and the popular divide-andchoose (McAfee, 1992), a sequential move mechanism. Over all measures, divide-andchoose is superior to winner's-bid auction. The performance of the winner's-bid auction is affected mainly by subject's bounded rationality and not by coordination failure. Divide-and-choose is affected by reciprocity issues and not by a lack of subject's sequential rationality. Contrary to theoretical predictions, divide-and-choose gives no advantage to the first-mover.

Our study will likely impact the practice of fair division. In particular, smartphone and computer applications are attempting to provide users with arbitration mechanisms to solve the type of allocation problems we consider in our study (e.g., Fair Outcomes Inc., 2007-2013; Splitwise Inc., 2014; and more, as Spliddit, 2014, are under construction). Some of these mechanisms theoretically deliver desirable outcomes. However, theory does not allow one to differentiate them from competing proposals. Our experimental study fills this need. We are able to document sharp differences in the performance, in a laboratory environment, of some of the most prominent mechanism available. Behavioral biases exhibited by subjects in our experiments, affect different mechanisms in different degrees. As a consequence, theoretically equivalent mechanisms, turn out to be significantly different in practice. Curiously, none of the services cited above offers our best performing mechanism. Our results also open the possibility to design new mechanisms that try to minimize the effect on their performance of the behavioral biases that we observe (see Sect. 5).

The allocation of one object among two agents is equivalent to the allocation of two objects among two agents with unit demands-receiving no object is another indivisible good in the former. We take advantage of this equivalence and frame our experiments as the allocation of a social endowment of two objects among two agents, when each agent receives exactly one object and there is the possibility of monetary compensation-notice that our results also inform the allocation of rooms and division of rent among two roommates who collectively lease an apartment (Abdulkadiroğlu et al., 2004). We find our environment more appropriate for our experimental setting; having two objects allows us to avoid, to some extent, agents' non-monetary incentives to "win" items, which is documented in auction settings (e.g., Cooper and Fang, 2008; Roider and Schmitz, 2012). For simplicity of exposition in this introduction, we use the language of allocation of a single object.

As mentioned above, we assume complete information. In situations like the dissolution of a long standing partnership or a marriage, agents may know each other well enough so their actions in the "game" induced by an allocation mechanism clearly convey their intentions. It is well known that when these intentions are revealed in a game, reciprocity issues systematically affect agents' behavior (see Charness and Rabin, 2002, among many others). Thus, by assuming complete information, we concentrate on the evaluation of these effects across different mechanisms without the noise that would be introduced by the asymmetry of information in our laboratory setting. Our results confirm that these issues are relevant and have to be taken into consideration when design- 
ing mechanisms for common-ownership distributive situations in which one expects agents will know each other well.

We evaluate our mechanisms with two criteria. First is efficiency. Here this is simply that the agent who values the object the most receives it. Second is equity. Here, we evaluate whether the allocation obtained can be sustained as the outcome of a market in which both agents have an equal share of the aggregate income. These allocations, which we refer to as market allocations, are arguably the most normatively compelling in our environment (Thomson, 2010; Varian, 1976). They not only are efficient, but also, in our environment, they coincide with the set of envy-free allocations, i.e., those at which no agent prefers the allotment of the other agent to her own. They can be easily described as follows. An agent who values the object the most receives it and transfers the other agent an amount between half the low-valuation agent's valuation and half of the high-valuation agent's valuation. Thus, the set is isomorphic to an interval. In the right extreme of this interval, the agent who receives the object transfers half of her valuation to the other agent. This is the worst market outcome for the high-valuation agent and the preferred market outcome for the low-valuation agent. Symmetrically, in the left extreme of this interval, the agent who receives the object transfers half of the lowvaluation agent's valuation to the other agent. This is the worst market outcome for the low-valuation agent and the preferred market outcome for the high-valuation agent (See Sec. 2 for details).

We evaluate the performance of two of the most prominent mechanisms that theoretically obtain market outcomes among strategic rational agents. Our first mechanism, the winner's-bid auction, operates as follows: both agents simultaneously bid for the object; then, an agent with the highest bid receives the object and pays her bid to the other agent. The set of limit Nash equilibria of the game induced by this mechanism for some given valuations, which is a sensible prediction here, is exactly the whole set of market allocations with respect to the true preferences (see Sec. 2.2). Our second mechanism, divide-and-choose, operates as follows: a randomly selected first-mover, which we refer to as "divider," proposes a transfer from the agent who receives the object to the other agent; then the second-mover, which we refer to as "chooser," decides whether to get the object and make the proposed transfer or to give up the object and get the transfer. The outcome in sub-game perfect equilibria of the game induced by this mechanism for some given valuations is the preferred market outcome for the proposer with respect to true preferences (see Sec. 2.2).

Both mechanisms we evaluate are intended to provide a form of endstate justice, for their equilibrium outcomes are market allocations. One can argue that divide-andchoose lacks procedural justice, however. After divider and chooser are selected, the mechanism loses symmetry. Not only do strategy spaces for the agents and timing of their actions differ, but also the proposer gains a considerable advantage, i.e., has the power to enforce her preferred market allocation (see Moulin, 2006, for a related discussion). Thus, theory provides a clear benchmark for the evaluation of these mechanisms: (i) the winner's-bid auction should provide a market allocation, free of any bias prede- 
termined by the mechanism designer; and (ii) divide-and-choose should provide a market allocation that is biased towards the proposer. Our study is the first to evaluate the extent to which this normative ranking based on equilibrium predictions is realized in an experimental environment.

Our first result is that divide-and-choose is superior to winner's-bid auction over all measures. Divide-and-choose obtains $81 \%$ market allocations and $85 \%$ efficient allocations. The more procedurally fair winner's-bid auction obtains $41 \%$ market allocations and $73 \%$ efficient allocations. The differences are statistically significant. Our second result is that the winner's-bid auction is affected by subjects underbidding and not by coordination failure. Symmetry turns out to be a costly feature for the this mechanism. Among boundedly rational players, as in our experiments, it induces a distortion caused by the simultaneity of play. Our data suggest that this distortion slowly improves over time, but does not improve to the level of divide-and-choose. This observation not only explains the loss of efficiency and competitiveness of the winner's-bid auction, but also points in a precise direction for its improvement (see Sec. 5). Our third result is that divide-and-choose is affected mainly by reciprocity issues. Even though divide-and-choose performs better than the winner's-bid auction, it obtains inefficient allocations with positive probability. Essentially, in the subgame perfect equilibrium of the divide-and-choose game, the chooser is nearly indifferent among the bundles selected by the proposer. Thus, when the proposer selects a proposal that is close to the subgame perfect proposal, the chooser has little incentive to choose the proposer's best bundle among the proposed ones. This "rejection strategy" induces a considerable loss for the proposer and is responsible for the majority of inefficient outcomes. This suggests that the performance of the mechanism may be improved by returning some symmetry without losing the sequentiality of play (see Sec. 5). Finally, our fourth result is that divide-and-choose, contrary to theoretical predictions, exhibits no first-mover advantage. Indeed, if at all, there is a second-mover advantage. In order to have a comparable benchmark to evaluate the mechanism's bias towards the first mover, we also run experiments on the simple ultimatum bargaining adapted to our environment with indivisibilities. As predicted by theory, and in contrast to the divide-and-choose, ultimatum bargaining, gives a considerable advantage to the first-mover.

Our winner's-bid auction is an intuitive mechanism whose non-cooperative equilibria are efficient both when agents know each other well and when information is incomplete and agents have independent private values. It belongs to the family of $\alpha$-auctions, where $\alpha \in[0,1]$. These auctions operate as follows. Ask both agents to report bids for the object; then, an agent with the highest bid receives the object and transfers the other agent the $\alpha$ convex combination between the highest and the lowest bid. In an independent private-value setting, all these auctions are ex-post-efficient, interim-individuallyrational, and incentive-compatible for a non-trivial set of ownership distributions that contains and is centered in the symmetric ownership case (Cramton et al., 1987). When information is complete, each $\alpha$-auction is strategically equivalent to a direct mechanism that selects a market allocation for the reported preferences (see Sec. 2). The equi- 
libria of all these market mechanisms for a given preference profile is exactly the set of all market allocations for the true preferences (Tadenuma and Thomson, 1995). ${ }^{1}$

Our divide-and-choose mechanism is the adaptation to our environment of the popular cake cutting procedure that bears the same name. It is commonly imbedded in partnership contracts as a buy-sell clause (de Frutos and Kittsteiner, 2008). There are references to applications of this principle back to Greek mythology and in modern times as the "Law of the sea" (Brams and Taylor, 1996). When agents know each other well, the mechanism produces efficient allocations that provide a form of end-state justice (Crawford, 1977; Crawford and Heller, 1979). Under incomplete information the mechanism may produce inefficient allocations, which necessarily violate the no-envy principle (McAfee, 1992). Remarkably, if agents are risk averse, the mechanism is predicted to exhibit a second-mover's advantage (McAfee, 1992). Thus, again one can make an argument, not only in terms of efficiency, but also in terms of procedural justice, favoring the winner's-bid auction over divide-and-choose under incomplete information (Che and Hendershott, 2008).

There is relatively little experimental work in the area of common-ownership problems under complete information. Guth et al. (1982) study the outcomes of the divideand-choose mechanism for the allocation of a set of indivisible "chips" that have different value for proposer and chooser. ${ }^{2}$ Their results are qualitatively consistent with ours; they observe responders' willingness to reject proposals. Our experimental design differs in two dimensions. First, in our experiments subjects can propose arbitrary transfers and thus divide-and-choose results can be compared with those of the winner's-bid auction. This comparison is a central contribution of our paper. Second, in our experiments for the divide-and-choose mechanism, the role of the proposer is randomly assigned among all subjects as opposed to being randomly assigned among all high-valuation agents as in Guth et al. (1982). Thus, our experiment can answer the question whether the secondmovers in divide-and-choose are more prone to reject inequality increasing proposals that have low rejection cost (only available to low-valuation second-movers) than equality generating proposals that have low rejection cost (only available to high-valuation second-movers). Moreover, since in our experiment both high and low valuation agents get to be first and second movers, we are able to evaluate the first-mover bias of the mechanism. In Guth et al. (1982) it is not clear whether differences in earnings should be attributed to proposer bias or valuation structure. Herreiner and Puppe (2009) investigate whether market allocations result from an "infinitely many proposals" bargaining mechanism under a time limit. They document that this mechanism achieves few market allocations. However, it is difficult to interpret these results, for it is not clear that Nash equilibrium outcomes of this bargaining procedure are market allocations. Schnei-

\footnotetext{
${ }^{1}$ Results in Tadenuma and Thomson (1995), which concern the allocation a single object, have been extended to environments with multiple objects and preferences that may not be quasi-linear (Āzacis, 2008; Beviá, 2010; Velez, 2011; Fujinaka and Wakayama, 2012; Velez, 2013). More recently, the possibilities of an agent to manipulate these mechanisms has been quantified (Andersson et al., 2010, 2012).

${ }^{2}$ Guth et al. (1982) refer to the divide-and-choose games as "complicated ultimatum games."
} 
der and Krämer (2004) and Dupuis-Roy and Gosselin (2009, 2011) experimentally evaluate the performance of the divide-and-choose mechanism. However, in their environment, monetary compensation is not possible. Thus, their experiments are silent about the performance of this mechanism in the distributive situations that motivate our study. Finally, in an incomplete information setting Kittsteiner et al. (2012) compared the performance of the winner's-bid auction and the divide-and-choose mechanism. The result there is that divide-and-choose weakly dominates the auction in terms of percentage of efficient allocations achieved in laboratory experiments. However, the difference is not large and only weakly statistically significant. Our results show that when players know each other well, the difference in performance is substantial and significant.

The remainder of the paper is organized as follows. Section 2 introduces the model and mechanisms we study. Section 3 presents our experimental design. Section 4 presents our results. Section 5 discusses our results and concludes.

\section{Model}

We consider two agents, $\{1,2\}$, who collectively and symmetrically own two objects $\{A, B\}$. This framework contains as a particular case a partnership dissolution problem, in which one object, say $A$, corresponds to staying out of the company and the other, $B$, retaining the company. The main reason to frame our experiments as the allocations of two goods, is that in this way we avoid, to some extent, winning motivation among participants. This equivalent formulation also highlights the relevance of our results for general problems of allocation of two indivisible goods as that of room allocation and rent division among roommates.

We assume that each agent receives exactly one object and either transfers or receives an amount of money to or from the other agent. Agents have preferences over the bundles of object and money; we adopt the convention that in a bundle $(x, \alpha)$, where $x \in \mathbb{R}$ and $\alpha \in\{A, B\}, x$ represents the amount that an agent transfers to the other agent. That is, when we say that agent $i$ receives bundle $(x, \alpha)$ with $x>0$, agent $i$ transfers $x$ to the other agent; if $x<0$, agent $i$ receives $|x|$ from the other agent. We assume that agents have quasi-linear preferences over bundles of an object and money. Consistently with our notation, agent $i$ 's utility of bundle $(x, \alpha)$ is $u_{i}(x, \alpha)=v_{i}^{\alpha}-x$, where $v_{i}^{\alpha}$ is agent $i$ 's valuation for object $\alpha$. We assume for simplicity that each agent's valuation for object $A$ is 100 .

We denote agents' allotments of money by $x_{1}$ and $x_{2}$, respectively. Since transfers are budget balanced, $x_{1}+x_{2}=0$.

It is convenient for our purpose to keep track of agents' net value of object $B$, i.e., the amount of money $x_{i}^{B}$ such that $v_{i}^{B}-x_{i}^{B}=v_{i}^{A}+x_{i}^{B}$ (agent $i$ is indifferent between paying $x_{i}^{B}$ for $B$ or receiving $A$ and being paid $\left.x_{i}^{B}\right)$. Since we normalize $v_{i}^{A}=100$, then $x_{i}^{B}=\left(v_{i}^{B}-\right.$ 100)/2. Let $\underline{x}^{B}$ and $\bar{x}^{B}$ be the minimum and maximum of $x_{1}^{B}$ and $x_{2}^{B}$, respectively. Since both agents have equal values for $A$, then having the higher valuation for $B$ is equivalent to having a higher net-valuation for $B$. 
An allocation is efficient if there is no other allocation that both agents weakly prefer and at least one agent strictly prefers. In our environment, the set of efficient allocations is that at which an agent with maximal valuation for object $B$ receives object $B$. When agents have different net valuations, one can graphically represent the set of efficient allocations by means of the transfer from the agent who receives object $B$, i.e., a high net-valuation agent, to the other agent. The set of efficient allocations at which both agents have non-negative utility is that in which a high net-valuation agent transfers between -100 and $\max \left\{v_{1}^{B}, v_{2}^{B}\right\}$ (Figure 1).

\subsection{Market allocations}

We are interested in the set of allocations that can be sustained as competitive equilibria in which each agent has an equal share of the aggregate income, i.e., the outcomes of a market with symmetric endowments. That is, there are prices $p_{A}$ and $p_{B}$ for the objects; each agent has an income $\frac{p_{A}+p_{B}}{2}$ and chooses between buying $A$ at $p_{A}$ or buying $B$ at $P_{B}$; and market clears. These allocations, which we refer to as market allocations, were proposed by Foley (1967) in order to achieve no-envy, i.e., that no agent prefers the allotment of the other agent to her own (here both agents have equal budget sets). It is well known that in our environment market allocations are efficient and coincide exactly with the set of envy-free allocations (Svensson, 1983). Thus, one can easily characterize them by means of the two no-envy conditions, i.e., no agent prefers the other's allotment to her own. These two conditions are equivalent to the agent who receives $B$ transferring an amount to the other agent in the interval $\left[\underline{x}^{B}, \bar{x}_{B}\right]$ (Figure 1). Of course in an efficient allocation an agent with high valuation for $B$ receives $B$. For simplicity assume that $v_{1}^{B}<v_{2}^{B}$, so agent 2 receives $B$ at each efficient allocation. Agent 1 is indifferent between bundle $\left(B, \underline{x}^{B}\right)$ and $\left(A,-\underline{x}^{B}\right)$. If agent 2 transfers $t_{B}<\underline{x}^{B}$ to agent 1 , then agent 1 would prefer getting $B$ and transferring $t_{B}$ to agent 2 to getting $A$ and receiving $t_{B}$. Thus agent 1 would envy agent 2 . Symmetrically, if agent 2 trasnfers $t_{B}>\bar{x}_{B}$ to agent 1 , then agent 2 would envy agent 1 .

\subsection{Popular mechanisms and market allocations}

We are interested in experimentally testing mechanisms to obtain market allocations. A first approach that one can attempt is to directly ask agents for their valuations, with their reports calculate the market outcomes for the reported values, and then select a given market allocation. Unfortunately, it is known that it impossible to do this in an incentive compatible way. That is, if one asks agents for their valuations and selects a market allocation for the reported values, generically there will be at least one agent who benefits by lying about her preferences (Alkan et al., 1991; Tadenuma and Thomson, 1995). An alternative approach is to use mechanisms whose non-cooperative equilib-

rium outcomes are always market allocations. The following two mechanisms achieve this. They have been focal in the literature on partnership dissolution (Cramton et al., 1987). 


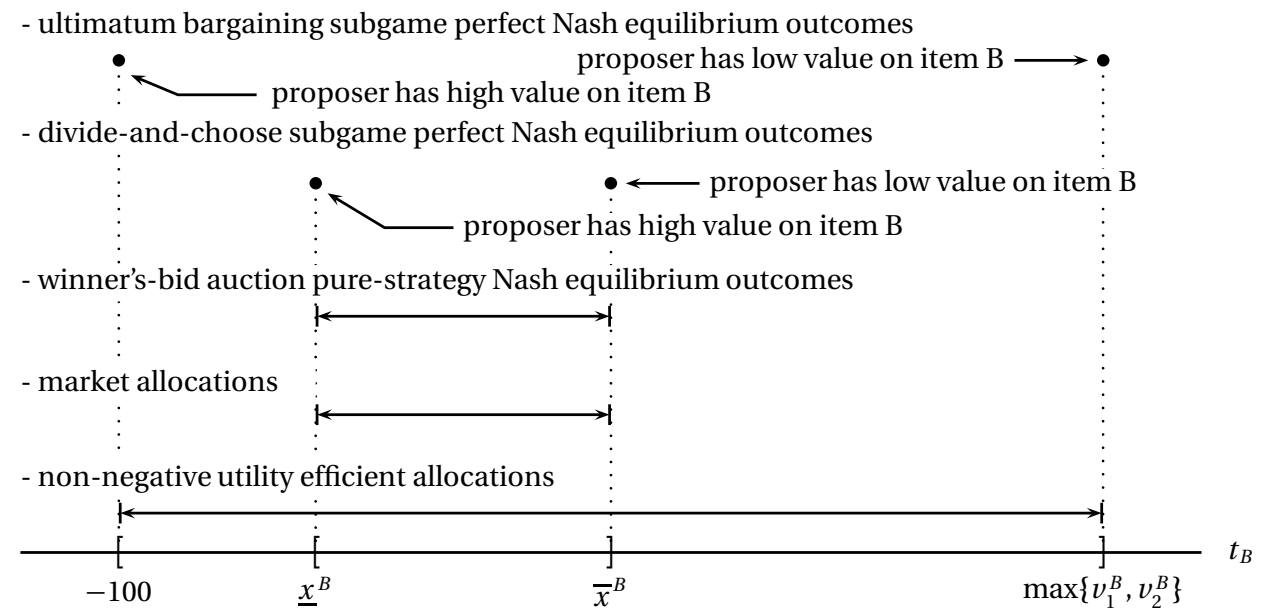

Figure 1: Efficient allocations, market allocations, and non-cooperative equilibrium outcomes from popular mechanisms. When $\underline{x}^{B}<\bar{x}^{B}$, the agent with the highest net valuation for $B$ receives $B$ at each efficient allocations. Thus, efficient allocations can be graphically represented by means of $t_{B}$, the transfer from the agent who receives $B$ to the other agent.

Winner's-bid auction: Both agents are asked to simultaneousy bid for object B (bids can be negative). Then, an agent with a highest bid receives object $B$ and transfers her bid to the other agent. In our experimental setting we break ties in favor of the agent with true higher valuation for $B$.

The set of pure-strategy Nash equilibrium outcomes of the game induced by our winner's-bid auction, i.e., the one in which we break ties in favor of the true high valuation agent, is exactly the set of market allocations (Figure 1). In equilibrium both agents report equal bids in the interval $\left[\underline{x}^{B}, \bar{x}^{B}\right] .^{3}$ Intuitively, agents will not coordinate on an inefficient allocation because in that case there is always an agent who prefers the consumption of the other agent. By bidding just above or below the other agent, an agent can essentially guarantee to obtain the other agent's allotment. An agent with high value of object $B$ will never bid more than $\bar{x}^{B}$ and receive $B$. Otherwise, she could just bid $\bar{x}^{B}$ and either pay less for $B$ or let the other agent get $B$ and transfer her no less than $\bar{x}^{B}$. An agent with low value of object $B$ will never bid less than $\underline{x}^{B}$ and receive $A$. Otherwise, she could just bid $\underline{x}^{B}$ and get $B$ and transfer $\underline{x}^{B}$ to the other agent, who must have been bidding just above her.

${ }^{3}$ Depending on the way one breaks ties when bids are equal, the bidding game induced by the winner'sbid auction may have no pure-strategy Nash equilibria. A sensible prediction for these games, that intuitively bypasses the role of the tie-breaker, is limit equilibria (Radner, 1980; Fudenberg and Levine, 1983). Independently of the tie breaker, the set of limit equilibrium outcomes of the winner's-bid auction is again the set of market allocations with respect to true preferences (see Velez, 2013, for a general characterization of limit equilibria for envy-free mechanisms). 
Divide-and-choose. A randomly selected agent, the proposer, names $x \in \mathbb{R}$ that determines two bundles, $(x, B)$ and $(-x, A)$, which will be the final allotments for the agents. Then, the second agent, the chooser, selects which bundle to receive. The proposer receives the residual allotment.

A sensible prediction for the sequential game induced by the divide-and-choose mechanism for utility maximizing agents is sub-game perfect equilibria. If the agent who has the higher valuation for $B$ is the proposer, she will propose a transfer $\underline{x}^{B}$ and the chooser selects $\left(-\underline{x}^{B}, A\right)$. Symmetrically, if the proposer is the agent with lower valuation for $B$, she will propose $\bar{x}^{B}$ and the chooser will select $\left(\bar{x}^{B}, B\right)$. Intuitively, the proposer knows that contingent on proposal $x$, the chooser will get the best bundle from $(x, B)$ and $(-x, A)$. A proposer with high valuation for $B$ will propose the lowest $x$ that incentivizes the other agent to select $(-x, A)$. Recall that the agent with low valuation for $B$ is indifferent between $\left(\underline{x}^{B}, B\right)$ and $\left(\underline{x}^{B}, A\right)$. Thus, if the high valuation agent proposes a transfer $x<\underline{x}^{B}$, the chooser will choose $(x, B)$. If the high valuation agent proposes a transfer $x>\underline{x}^{B}$, the chooser will choose $(-x, A)$. In both cases the high value proposer is better off getting $\left(\underline{x}^{B}, A\right)$, which she can guarantee by proposing just above $\underline{x}^{B}$. Thus, the only subgame perfect equilibrium outcome when the agent with higher valuation for $B$ proposes, is the left corner of the set of market allocations. Symmetrically, the only subgame perfect equilibrium outcome when the agent with lower valuation for $B$ proposes, is the right corner of the set of market allocations (Figure 1).

As a benchmark for evaluating a possible first-mover bias of the divide-and-choose mechanism, we consider the popular and simple form of bargaining known as ultimatum bargaining.

Ultimatum bargaining: A randomly selected agent proposes an allocation of the objects with their monetary transfers (specifies both who gets which object and the transfer from the agent who receives $B$ to the other agent). Then the other agent decides to accept or not the proposal. If the second agent rejects the proposal, both agents receive zero payoff.

A sensible prediction for the sequential game induced by the ultimatum bargaining mechanism for utility maximizing agents is again sub-game perfect equilibria. Here the proposer simply extracts all possible surplus and leaves the chooser with zero utility. If the agent with higher valuation for $B$ is the proposer, she will propose to receive $B$ and will ask the other agent to transfer her all her value for object $A$, i.e., 100. If the agent with lower valuation for $B$ is the proposer, she will propose to receive $A$ and will ask the other agent to transfer her all her value for object $B$, i.e., $\max \left\{v_{1}^{B}, v_{2}^{B}\right\}$ (Figure 1).

It is known that agents may not exhibit Nash behavior in simultaneous move games or reason by backward induction in sequential move games. However, it is not clear which of these, or other behavioral effects, like reciprocity or bounded rationality, will affect the most the performance of winner's-bid auction and divide-and-choose. Our experimental design allows us to evaluate these two mechanism in comparable settings. ${ }^{4}$

\footnotetext{
${ }^{4}$ It is also relevant to consider the possibility that a mechanism whose non-cooperative equilibrium out-
} 


\begin{tabular}{cccccc}
\hline Mechanism & Efficient & $\begin{array}{c}\text { market } \\
\text { allocations } \\
\text { predicted }\end{array}$ & Symmetric & $\begin{array}{c}\text { Coordination } \\
\text { required }\end{array}$ & $\begin{array}{c}\text { Reciprocity } \\
\text { issues }\end{array}$ \\
\hline Winner's-bid auction & yes & yes & yes & yes & no \\
Divide-and-choose & yes & yes & no & no & yes \\
Ultimatum bargaining & yes & no & no & no & yes \\
\hline
\end{tabular}

Table 1: Properties of mechanisms we experimentally evaluate. The winner's-bid auction is the only mechanism to satisfy three normative theoretical properties. Because of its simultaneity, it is also the only mechanism to require coordination.

Table 1 summarizes the three mechanisms that we experimentally study. The winner'sbid auction is symmetric, i.e., in its induced game each agent has the same action space. It achieves in non-cooperative equilibria market allocations, which are always efficient. The equilibria of the winner's-bid auction game requires agents coordination. Since it is a simultaneous move game, no agent ever replies to the action of another player and is affected by the perceived intention of that action. Thus, one can expect that reciprocity is not an important source of deviations from Nash behavior. The divide-andchoose mechanism achieves in non-cooperative sub-game perfect equilibria market allocations, which are efficient. After the proposer is determined, the induced game is not symmetric. Since the game is sequential, it requires no coordination of players. Moreover, the chooser's action may be affected by the perception of the proposer's intentions. The ultimatum bargaining mechanism achieves in non-cooperative equilibria the extremes of the set of efficient allocations at which each agent has non-negative utility. These allocations are not market allocations. Similarly to the divide-and-choose this game is sequential and thus requires no coordination and is affected by reciprocity issues.

\section{Experimental Design}

This experiment implemented the aforementioned theoretical environment with each of the three mechanisms. Subjects, randomly selected each round into groups of two, chose how to allocate two indivisible items ${ }^{5}$ with possible transfer payments. In all possible allocations, each subject received exactly one item. ${ }^{6}$ Each period, subjects received

comes are not market allocations may produce them because of the behavioral deviations that agents usually exhibit in the laboratory. Our experiment with ultimatum bargaining serves this purpose. It turns out that both divide-and-choose and winner's-bid auction perform significantly better than ultimatum bargaining in terms of the percentage of market allocations obtained. For clarity in the presentation we present results for this last mechanisms only in the context of evaluating the first-mover bias.

${ }^{5}$ We chose to have subjects bid over two items to match the generalized theoretical environment more closely and reduce the possibility that of subjects are motivated by the non-monetary desire to "win" an item (the utility of winning, e.g., Cooper and Fang, 2008; Roider and Schmitz, 2012).

${ }^{6}$ In the case of ultimatum bargaining if a proposal was rejected each subject received nothing. However, all ultimatum bargaining proposals required that each subject receive exactly one item 


\begin{tabular}{ccc}
\hline Player & $\begin{array}{c}\text { Value of } \\
\text { Item A }\end{array}$ & $\begin{array}{c}\text { Value of } \\
\text { Item B }\end{array}$ \\
\hline Player 1 & 100 & 120 \\
Player 2 & 100 & 40 \\
\hline
\end{tabular}

Table 2: A sample valuation. In this valuation, one subject valued item A at 100 and item $B$ at 120 . As in our theoretical environment, the other subject with whom she is paired had the same value for item A, but valued item B at 80. Each player had an equal chance of receiving the high value on item B for any period. Valuations were common knowledge to both players. This specific valuation structure ("valuation 3") was used for periods $21-30$.

points for acquiring an item, equal to their value of that item. Thus, the values for each item are induced values.

The experiment consisted of 50 periods, with 5 different valuations occurring sequentially over 10 consecutive periods each. For any period, for each grouping of subjects, one subject was randomly assigned the high value on item $B$, the other was assigned the low value on item B. Thus a subject's value on item B could change for any period, but the valuation structure (the high and low values for item B) remained the same for the 10 periods. Subjects always valued item A at 100. In order of appearance, the pairing of subject values for item B were $(40,80),(120,160),(40,120),(160,160)$, and $(0,40) .^{7}$ Table 2 provides an example valuation, the third valuation used in the experiments. Here, both subjects have the same value for item A, but their values for item B are different: player 1 has the high value for item B (120 points), and player 2 has the low value for item B (40 points).

To avoid incentives associated with repeated play, subjects were randomly re-assigned to each other at the beginning of each period. Subjects were instructed that they were to be randomly rematched each period, and no identifying information (e.g., subject number) was disclosed to a subject about her match in any round. Each period began with each subject seeing the valuation for the period.

\subsection{Winner's-bid auction procedures}

In the winner's-bid auction session, after observing the valuation for the period, subjects simultaneously submitted their bids for item B. The subject with the higher bid received item B, and the subject with the lower bid received item A. In this way, the winner's-bid auction is a first-price auction to acquire item $B$ over item $A$. In the case of equal bids, the

\footnotetext{
${ }^{7}$ The ordering of the valuations was chosen at random, but remained constant across all three mechanisms. The valuations were specifically chosen to allow for two possibilities where both players value item A more than B $(40,80)$ and $(0,40)$, two possibilities where both players value item B more than A $(120,160)$ and $(160,160)$, and one where one player one player values B more than A and one values A more than B $(40,120)$. Additionally the fourth valuation $(160,160)$ was chosen to allow an environment where there is one unique equilibria over all three mechanisms, and coordination should not be an issue.
} 
subject with the higher value of item B received item A. ${ }^{8}$ The subject who received item $\mathrm{B}$, then pays the subject who receives item A the full amount of her bid. ${ }^{9}$

After submitting a bid, each subject was allowed to submit a possible value for the other player's bid. The experimental software then displayed the outcome (i.e., who gets which item, what amount is transferred for each player, each players' earnings for that period) that would occur with those two bids as well as a table that showed all possibilities that could happen if the other player's bid were below, equal to, or above the subject's bid (see Figure 2). After a subject viewed these possibilities, she could chose to confirm her bid, or chose an alternate bid. If she chose an alternate bid, the process repeated. The process ended when a subject confirmed her bid.

After both subjects submitted their bids, they were asked to guess what they believed was the other subject bid. ${ }^{10}$ If they guessed correctly they received a small bonus of 5 points. The value of this bonus was deliberately chosen to be small, so that subjects did not alter their bidding strategy to receive the bonus. After both subjects submitted their guesses they saw the outcome of their bidding. They learned what the other player bid, which items they both received, the transfer payment between them, their earnings, and their partners' points earned. Subjects learned if they received a bonus for guessing the other player's bid correctly, but did not learn if the other player had received the bonus for guessing their bid correctly. After this information was disclosed, a new period began. This process continued for 50 periods.

\subsection{Divide-and-choose procedures}

In the divide-and-choose session, at the beginning of each period, one subject was randomly selected to be the divider. That subject chose which item should receive a transfer and the amount of that transfer. Transfer payments were limited so that no subject received negative earnings for each period (so, for example in Table 2, the divider could propose whomever receives item A could get a transfer up to 80 , the minimum value of $B$, or whomever receives item B could get a transfer up to 100, the minimum value of A).

After one subject made a proposal, she saw a table of possible outcomes similar to Figure 2 that displayed the two possible outcomes (i.e., who gets which item, what amount is transferred for each player, each players earnings for that period) when the other subject choose to take item A or item B. The subject had the opportunity to confirm her decision or make another one. If she chose to try another proposal, the process

\footnotetext{
${ }^{8}$ In the case of the fourth valuation where both subjects value item B at 160, one subject was randomly selected to win ties, this was known before bids were submitted (i.e., ex-ante). The tie-breaking rules were chosen to allow for easier analysis of equilibrium.

${ }^{9}$ To eliminate the possibility of grossly negative earnings, bids were restricted so that no bid could be lower than the opposite of twice the value of item A (-200, always) and no bid could be higher the twice the maximum value of item B (varies by valuation, i.e, 160, 320, 240, 320, and 80 for each valuation, respectively).

${ }^{10}$ Subject guesses appear to be unrelated any other part of their behavior. The data are not meaningful and not presented here. Subjects are clearly not best responding to their guesses; this result is consistent with Costa-Gomes and Weizsäcker (2008) who study this issue in detail.
} 


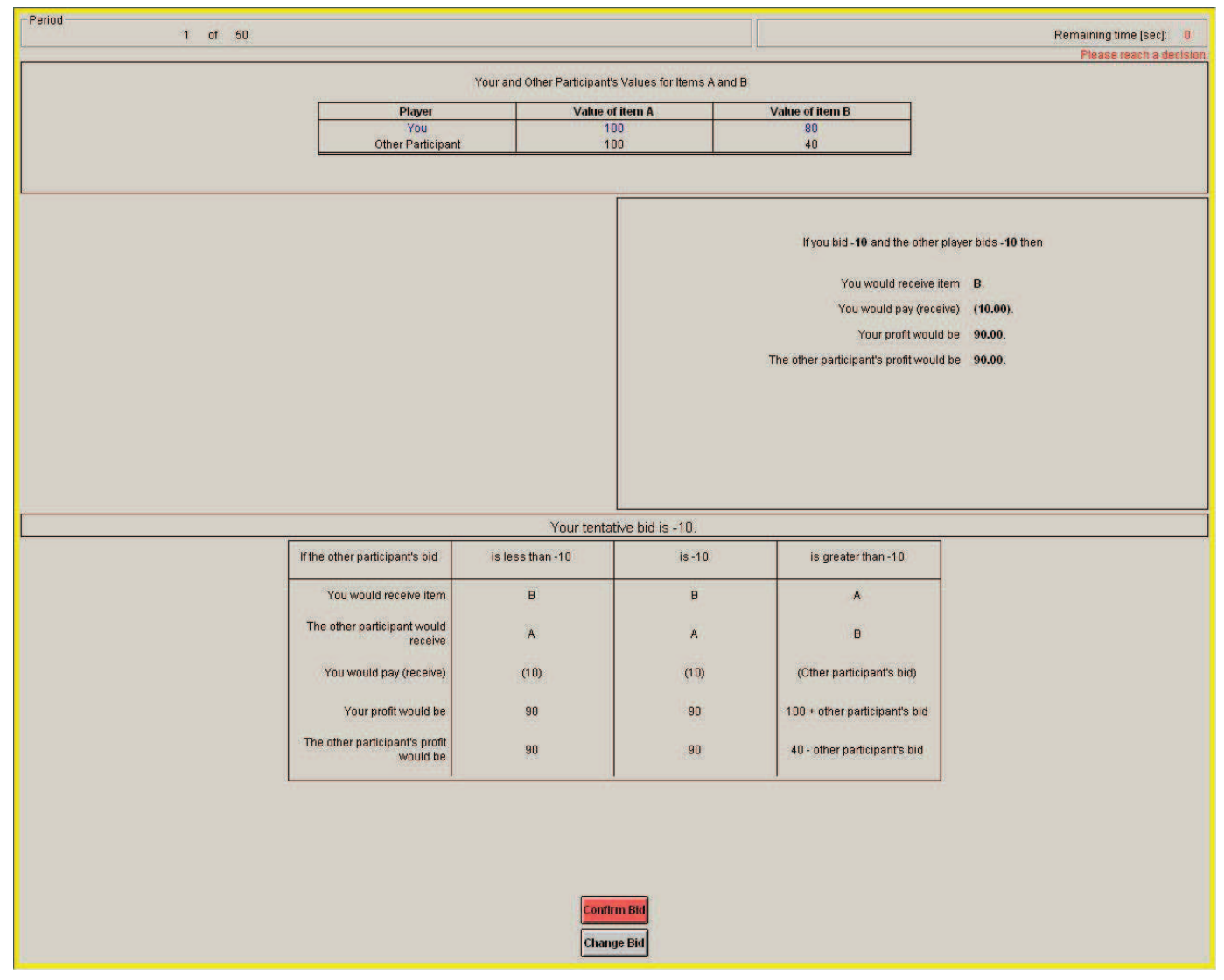

Figure 2: Confirmation screen for subjects. Subjects have the option to review their bid and the possible outcomes associated with it after submitting their initial bid.

repeated until she confirmed a proposal. Once a proposal was confirmed, the other subject viewed the proposal. The display showed her two outcomes-both her own and the other subject's total earnings if she chose to take item A or item B. The chooser then had the opportunity to choose either item. After that decision was made, both subjects viewed the outcome of the period. They saw what the divider proposed, which item the chooser selected, the items and transfers received by each subject (if applicable) and the points earned by each subject for the period. After this information was disclosed, a new period began. This process continued for 50 periods.

\subsection{Ultimatum bargaining procedures}

In the ultimatum bargaining session, at the beginning of each period, one subject was randomly selected to be the proposer. That subject chose who received each item, and if any transfer payments should be paid from one subject to the other. Transfer payments were limited so that no subject could receive negative earnings for each period (so, for 
example in Table 2, player 1 cannot propose player 2 receive item A and pay player $1 \mathrm{a}$ transfer payment of 101 points, because that would result in player 1 receiving negative earnings).

After the proposer made a proposal, she saw a table of possible outcomes similar to Figure 2 that displayed the two possible outcomes (i.e., who gets which item, what amount is transferred for each player, each player's earnings for that period) when the other subject accepted or rejected her proposal. Note that in the case of rejection, the outcome was that both subject received no items and no points for the period. The proposer had the opportunity to confirm or modify the proposal. If she chose to modify, the process repeated until she confirmed a proposal. Once a proposal was confirmed, the other subject, the responder, viewed the proposal. The display showed her two outcomes-what happened if he chose to accept or reject the other subject's proposal. The responder then had the opportunity to accept or reject the proposal. After that decision was made, both subjects viewed the outcome of the period. They saw the proposer's proposal, whether the responder accepted or rejected that proposal, the items and transfers received by each subject (if applicable) and the points earned by each subject for the period. After this information was disclosed, a new period began. This process continued for 50 periods.

\subsection{End of experiment procedures}

Once the 50 periods were complete, subjects completed a survey about their opinions of the other players with whom they had been matched, the mechanism used, and their general feelings of what fairness means. They were also given the opportunity to provide a tip up to $\$ 5$, which was be doubled and divided among all other subjects. The final survey question told them they were to play one more period at a valuation 10 times greater than before and they voted on the mechanism to be used by all subjects for that round. Subjects in the ultimatum bargaining and divide-and-choose sessions voted between their current mechanism and the winner's-bid auction; subjects in the winner's-bid auction session voted between the winner's-bid auction and the ultimatum bargaining. Since only one mechanism was used per experimental session a brief description was provided of the other mechanism. After all subjects completed the vote, the winning mechanism was implemented for the final period. ${ }^{11}$ As carefully explained to the subjects a majority vote was required to change to the new mechanism, meaning the status-quo won all ties. ${ }^{12}$ After the high-stakes period subjects again completed more surveys, a demographic survey and a five-factor personality assessment (from John et al., 2008). ${ }^{13}$

\footnotetext{
${ }^{11}$ The results of this last period are not included in the data analysis.

${ }^{12}$ The status-quo won in all three sessions, though by a much smaller margin in the ultimatum bargaining session.

${ }^{13}$ Survey results are not reported in this paper. We did not find any interesting interactions between survey responses and mechanism type or subject behavior. They are available from the authors upon request.
} 


\begin{tabular}{lcc}
\hline Mechanism: & winner's-bid auction & divide-and-choose \\
\hline efficient outcomes & 437 & 594 \\
(percent) & $(0.728)$ & $(0.849)$ \\
market outcomes & 283 & 567 \\
(percent) & $(0.472)$ & $(0.810)$ \\
average profit (in points) & 99.917 & 102.40 \\
(standard error) & $(1.111)$ & $(1.128)$ \\
percent of maximum possible & 0.935 & 0.962 \\
profit (standard error) & $(0.005)$ & $(0.001)$ \\
\hline
\end{tabular}

Table 3: Summary of outcomes for each subject pair by divide-and-choose and winner's-bid auction mechanisms. Across all measures efficient outcomes, market outcomes, average profit and percent of profit realized, the divide-and-choose outperforms the winner's-bid auction.

All experiments were held at the Economic Research Laboratory (ERL) in the Economics Department at Texas A\&M University. Subjects were recruited using ORSEE software (Greiner, 2004) and made their decisions on software programmed in the z-tree language (Fischbacher, 2007). Subjects sat at computer terminals with dividers to make sure their anonymity was preserved. Subjects were 78 Texas A\&M undergraduates from a variety of majors, twenty-six subjects took part in the ultimatum bargaining session on October 21, 2010; twenty-four subjects took part in the winner's-bid auction session on October 22, 2010; twenty-eight subjects took part in the divide-and-choose session on April 12, 2012. Experiments lasted about three hours. Subject point values were totaled and converted to cash at the rate of 400 points $=\$ 1.00$, rounded up to the nearest dollar. Subject earnings ranged from $\$ 14.70$ to $\$ 33.80$ ( $\$ 25.44$ average earnings), $\$ 16.20$ to $\$ 31.70$ ( $\$ 27.65$ average earnings), $\$ 14.20$ to $\$ 33.80$ ( $\$ 26.40$ average), for the ultimatum bargaining, divide-and-choose, and winner's-bid auction sessions, respectively.

\section{Results}

Result 1. Over all measures, the divide-and-choose mechanism outperforms the winner'sbid auction mechanism.

Table 3 provides an overview for the performance of the divide-and-choose and winner's-bid auction over realized outcomes. Over all measures, efficient outcomes achieved, market outcomes achieved, average profit per subject pair and percent of profit realized per subject pair, divide-and-choose outperforms the winner's-bid auction. Figures $3(\mathrm{a}-\mathrm{c})$ show these results hold over all valuations and are not dependent on a specific valuation structure. (Recall that each mechanism was tested for 50 periods, divided into five 10-period segments with a different type of valuation structure.) For every valuation, subjects in divide-and-choose achieve a greater percentage of efficient outcomes realized, a greater percentage of market outcomes realized, and higher average payoffs realized. 


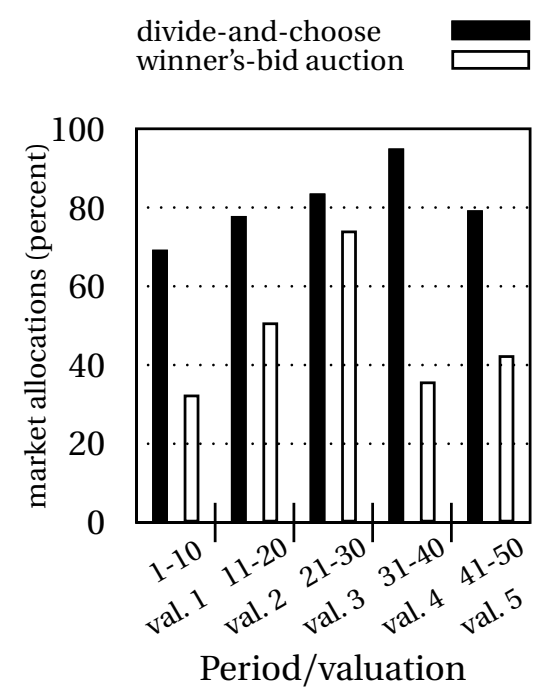

(a)

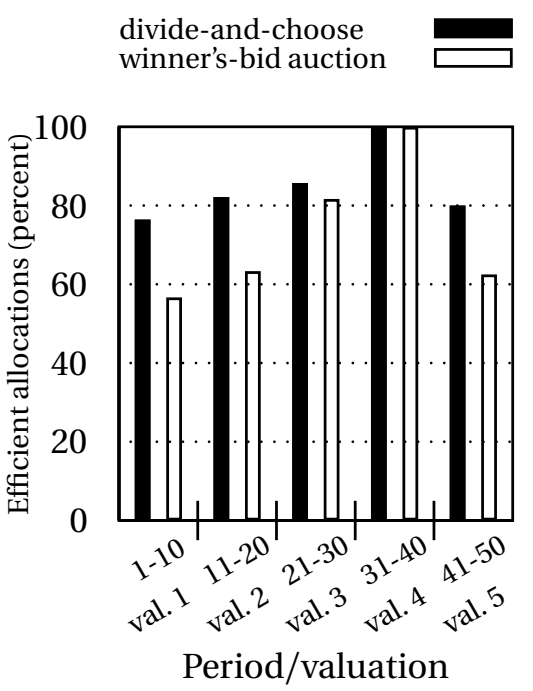

(b)

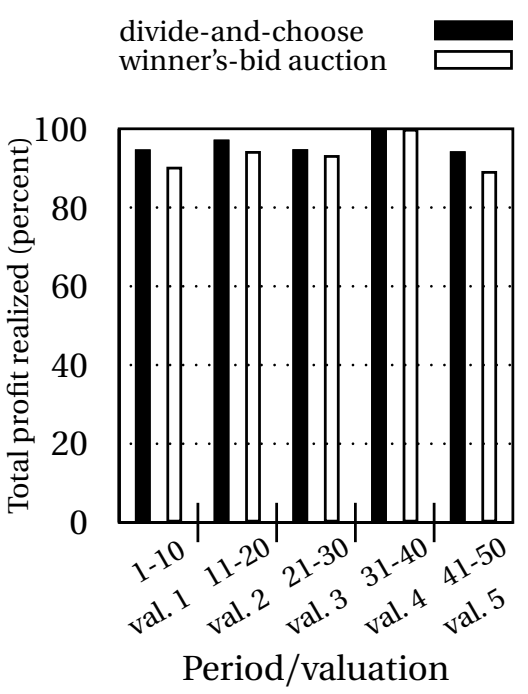

(c)

Figure 3: Percentage of market outcomes obtained, efficient outcomes obtained, and total profit realized under the divide-and-choose, winner's-bid auction, and ultimatum bargaining mechanisms by valuation type. In each session, over 50 periods, five valuations occurred sequentially for ten periods each. (a, left) For all valuations, the percentage of market valuations realized was highest for the divide-andchoose mechanism over all valuations; the winner's-bid auction was higher than the ultimatum bargaining. (b, middle) For each valuation, the divide-and-choose achieved the highest number of efficient outcomes. Ultimatum bargaining generally achieved more efficient outcomes than the winner's-bid auction, except for valuation 4. (c, right) For all valuations, the divide-and-choose mechanism realized the highest percentage of total profit; the winner's-bid auction achieved a higher percentage than ultimatum bargaining.

To determine statistical significance, we use regression techniques for panel data. Unless specified otherwise, we will use crossed random effects for each subject pair (i.e., a separate random effect for each subject), and one dummy variable for each period in our data (i.e., fixed effects), to control for idiosyncratic properties of certain subjects or periods, respectively. Formally, for binary outcomes we will use the regression model

$$
\operatorname{logit}\left(\operatorname{Pr}\left(y_{i j k}=1 \mid X_{i j k}, \zeta_{1 j}, \zeta_{2 k}\right)\right)=\beta X_{i j k}+\gamma_{i}+\zeta_{1 j}+\zeta_{2 k},
$$

where $y_{i j k}$ represents the outcome of the pairing of subject $j$, and subject $k$ in period $i$. The random coefficients $\zeta_{1 j} \sim N\left(0, \psi_{1}\right), \zeta_{2 k} \sim N\left(0, \psi_{2}\right)$ are determined for subject $j$ and subject $k$ by their positions in the mechanism. In this case subject $j$ is in the first position (e.g., higher value on item $\mathrm{B}$, or first mover) and $k$ is in the second position (e.g., lower value on item $\mathrm{B}$, or second mover); $\gamma$ is a vector of fixed effects for each period; $X_{i j k}$ contains other data of interest, such as mechanism type, and $\beta$ is a vector of coefficients.

A similar model is used for non-binary outcomes with the residual error term $\epsilon_{i j k} \sim$ $N(0, \theta)$.

$$
y_{i j k}=\beta X_{i j k}+\gamma_{i}+\zeta_{1 j}+\zeta_{2 k}+\epsilon_{i j k} .
$$

Table 4 shows the results of four regressions using the models described in equations 1 and 2. The variable of interest is the divide-and-choose term, a dummy variable 


\begin{tabular}{|c|c|c|c|c|}
\hline $\begin{array}{l}\text { Dependent } \\
\text { variable: }\end{array}$ & $\begin{array}{c}\text { Efficient } \\
\text { outcome } \\
\text { (1) }\end{array}$ & $\begin{array}{c}\text { Market } \\
\text { outcome } \\
\text { (2) }\end{array}$ & $\begin{array}{l}\text { Average } \\
\text { earnings } \\
\text { of pair } \\
\text { (3) }\end{array}$ & $\begin{array}{l}\text { Percent of } \\
\text { total possible } \\
\text { earnings } \\
\text { (4) }\end{array}$ \\
\hline Divide-and-choose $^{a}$ & $\begin{array}{l}0.992^{* * *} \\
(0.252)\end{array}$ & $\begin{array}{l}1.908^{* * *} \\
(0.261)\end{array}$ & $\begin{array}{r}2.687^{* * *} \\
(0.761)\end{array}$ & $\begin{array}{l}0.029^{* * *} \\
(0.008)\end{array}$ \\
\hline Regression Type? & logistic & logistic & linear & linear \\
\hline Fixed effects? ${ }^{b}$ & $\begin{array}{l}\text { each } \\
\text { period }\end{array}$ & $\begin{array}{l}\text { each } \\
\text { period }\end{array}$ & $\begin{array}{l}\text { each } \\
\text { period }\end{array}$ & $\begin{array}{l}\text { each } \\
\text { period }\end{array}$ \\
\hline $\begin{array}{l}\text { First random } \\
\text { effects term? }\end{array}$ & $\begin{array}{l}\text { subject with } \\
\text { high value }\end{array}$ & $\begin{array}{l}\text { subject with } \\
\text { high value }\end{array}$ & $\begin{array}{l}\text { subject with } \\
\text { high value }\end{array}$ & $\begin{array}{l}\text { subject with } \\
\text { high value }\end{array}$ \\
\hline $\begin{array}{l}\text { Second random } \\
\text { effects term? }{ }^{c}\end{array}$ & $\begin{array}{l}\text { subject with } \\
\text { low value }\end{array}$ & $\begin{array}{l}\text { subject with } \\
\text { low value }\end{array}$ & $\begin{array}{l}\text { subject with } \\
\text { low value }\end{array}$ & $\begin{array}{l}\text { subject with } \\
\text { low value }\end{array}$ \\
\hline
\end{tabular}

* Significant at the $10 \%$ level.

** Significant at the $5 \%$ level.

*** Significant at the $1 \%$ level.

a. Winner's-bid auction dummy variable is omitted.

b. Giving fixed terms for each valuation type (five dummy variables for valuations 1-5), and valuation within period (ten dummy variables for periods 1-10) does not significantly alter results. c. Sorting random effects by subject favored by mechanism (high value in auction, proposer in divide-and-choose) does not significantly alter regression results.

Table 4: Regressions of mechanism outcomes on type of mechanism, controlling for period fixed effects and subject random effects.

that indicates if the mechanism used is divide-and-choose; it indicates the difference between the divide-and-choose mechanism and the winner's-bid auction. The regressions confirm the results found in Table 3. The divide-and-choose mechanism achieves significantly more efficient and more market outcomes than the winner's-bid auction as well as higher earnings on two metrics; the coefficient for divide-and-choose in all regressions is positive and significant at the $1 \%$ level.

Result 2. The failure to achieve market and efficient outcomes in the winner's-bid auction mechanism is primarily due to subject underbidding relative to Nash, rather than a failure to coordinate over multiple Nash equilibria. The underbidding is especially predominant among those who have the low valuation on item $B$.

It is not obvious why subjects in the winner's-bid auction achieve market outcomes less than half of the time and efficiency only $72 \%$ of the time. Two explanations come to mind. Either subjects are having difficulty deducing how to play equilibrium strategies, or the multiplicity of equilibria leads to a coordination failure, causing disequilibrium among possible equilibrium strategies. 
There is little support for the coordination failure explanation. Figure 3 reveals only $36 \%$ of outcomes were market outcomes in Valuation 4, the one valuation with a unique Nash equilibrium and thus no coordination issues. On average for all other valuations, $50 \%$ of the outcomes were market outcomes. Regression analysis confirms that Nash equilibrium bids are not more likely in Valuation 4 (Table 5) -more on this below. ${ }^{14}$

Aggregate analysis provides evidence that subjects had great difficulty in playing equilibrium strategies; nearly half of all bids (597 of 1200, 50\%) were non-Nash (i.e., outside the range $\left.\left[\underline{x}^{B}, \bar{x}^{B}\right]\right)$. Non-Nash bids were slightly more common among subjects with the low valuation on item B (322 of $600,54 \%)$ than the high valuation $(275$ of 600 , $46 \%$ ). Most non-Nash bids (483 of 597, 83\%) were underbids, with low valuation subjects responsible for more underbids than high valuation subjects (267 vs. 216). Table 5 provides a multinomial logistic regression on these three bid types. The regression confirms subjects are more likely to make Nash bids when they have the high valuation on item B. ${ }^{15}$

The winner's-bid structure may be a reason for this deviation. With the winner's bid structure, as long as the high bid is a Nash bid, a market outcome, which is efficient, will be obtained. If the subject with the high value on item B proposes a Nash bid, there is no incentive for the low-value subject to bid over that value (or even bid that value) and there is no penalty for bidding below. Moreover, if the low value agent considers the scenario in which the other agent's bid is actually lower, by bidding low, she guarantees a higher payoff if she ends up winning the auction. Figure 4 provides a breakdown of the types of bids (above Nash, i.e., above $\bar{x}^{B}$; below Nash, i.e., below $\underline{x}^{B}$; and Nash) used by subjects with the high and low value on item averaged over the period within valuation. Low-value subjects do make more bids below Nash levels, roughly $15 \%$ more. Bids above Nash levels appear to be decreasing as subjects gain more experience within a valuation; if anything, subjects appear to be increasing their number of Nash bids. The regression in Table 5 shows that subjects are not reducing their below bids as they gain experience within a valuation (the coefficient on the period within valuation term is positive, though not significant), and that subjects with the low value on item B are more likely to make these below Nash bids.

The strategy of underbidding by the subject with the low value on item B is rather myopic. Ultimately, it provides an incentive for subjects with the high value to lower their bids. If they lower those bids below Nash levels but still above the other subject's bid, this can lead to efficient, but not market outcomes. If they bid under the other subject's bid, this leads to inefficiency. If dynamics such as these continue, with low-value subjects underbidding relative to Nash levels without any increase in the propensity to Nash bid, sophisticated high-value subjects will also underbid as a best response, and regardless

\footnotetext{
${ }^{14}$ This result is also confirmed by regression analysis of equilibrium outcomes: Valuations 1 and 4 are the least likely to result in market outcomes; there is no significant difference between Valuations 1, 4, and 5.

${ }^{15}$ Subjects with the low valuation on item B are more likely to overbid than play Nash (though not significantly so) and underbid ( $\mathrm{p}<0.01)$, the sum of these coefficients is negative and significantly different than $0(p=0.034)$.
} 


\begin{tabular}{|c|c|c|}
\hline Bid type: & $\begin{array}{c}\text { below Nash } \\
\text { bid }\end{array}$ & $\begin{array}{c}\text { above Nash } \\
\text { bid }^{\text {a }}\end{array}$ \\
\hline $\begin{array}{l}\text { period within } \\
\text { valuation }\end{array}$ & $\begin{array}{c}0.012 \\
(0.026)\end{array}$ & $\begin{array}{c}-0.296^{* * *} \\
(0.044)\end{array}$ \\
\hline $\begin{array}{l}\text { has high value } \\
\text { on item B }\end{array}$ & $\begin{array}{c}-0.503^{* * *} \\
(0.148)\end{array}$ & $\begin{array}{l}-0.147 \\
(0.226)\end{array}$ \\
\hline $\begin{array}{l}\text { valuation } 1^{\mathrm{b}} \\
(40-80)\end{array}$ & $\begin{array}{c}-1.599^{* * *} \\
(0.237)\end{array}$ & $\begin{array}{l}0.663^{*} \\
(0.386)\end{array}$ \\
\hline $\begin{array}{l}\text { valuation } 2 \\
(120-160)\end{array}$ & $\begin{array}{c}-1.477^{* * *} \\
(0.229)\end{array}$ & $\begin{array}{c}-1.607^{* * *} \\
(0.520)\end{array}$ \\
\hline $\begin{array}{l}\text { valuation } 3 \\
(40-120)\end{array}$ & $\begin{array}{c}-3.701^{* * *} \\
(0.280)\end{array}$ & $\begin{array}{c}-1.907^{* * *} \\
(0.468)\end{array}$ \\
\hline $\begin{array}{l}\text { valuation } 5 \\
(0-40)\end{array}$ & $\begin{array}{c}-2.359^{* * *} \\
(0.241)\end{array}$ & $\begin{array}{l}-0.208 \\
(0.395)\end{array}$ \\
\hline Type of regression? & \multicolumn{2}{|c|}{ Multinomial logistic } \\
\hline Fixed effects? ${ }^{b}$ & \multicolumn{2}{|c|}{ each valuation (shown above } \\
\hline First random effects term? & \multicolumn{2}{|c|}{ subject } \\
\hline Second random effects term? & \multicolumn{2}{|c|}{ none } \\
\hline observations & \multicolumn{2}{|l|}{1200} \\
\hline log likelihood & \multicolumn{2}{|l|}{-884.377} \\
\hline
\end{tabular}

a. Bids that are not below or above Nash bids are Nash bids. That type of bid is the base category in the regression. All coefficients should be interpreted as relative to Nash bid.

b. Valuation 4 is omitted for easy comparison to other valuations.

Table 5: Regression of bid type for winner's-bid auction on valuation, period within valuation, and subject's value on item $B$, controlling for subject random effects.

of how much experience subjects get within a valuation, the system will not converge to full equilibrium. ${ }^{16}$

Result 3. The failure to achieve market and efficient outcomes in the divide-and-choose is primarily due to the second-mover choosing against self-interest and efficiency, rather than the divider's failure to make market divisions. Nearly all of these suboptimal choices occur when the chooser receives less than one-third of the efficiency surplus. Consistent with inequality aversion, the chooser is far more likely to choose against self-interest and efficiency when holding the low valuation on item $B$.

With the divide-and-choose mechanism, there were 133 (of 700, see table 3) outcomes that were not market outcomes. Of these, 45 involved the divider proposing a

\footnotetext{
${ }^{16}$ This argument, which can sustain only deviations below Nash bids, is consistent with a Quantal Response Equilibrium (QRE) model (McKelvey and Palfrey, 1995). Brown and Velez (2013) theoretically and experimentally examine the policy implications of QRE behavior in a winner's-bid auction and alternative simultaneous move mechanisms.
} 

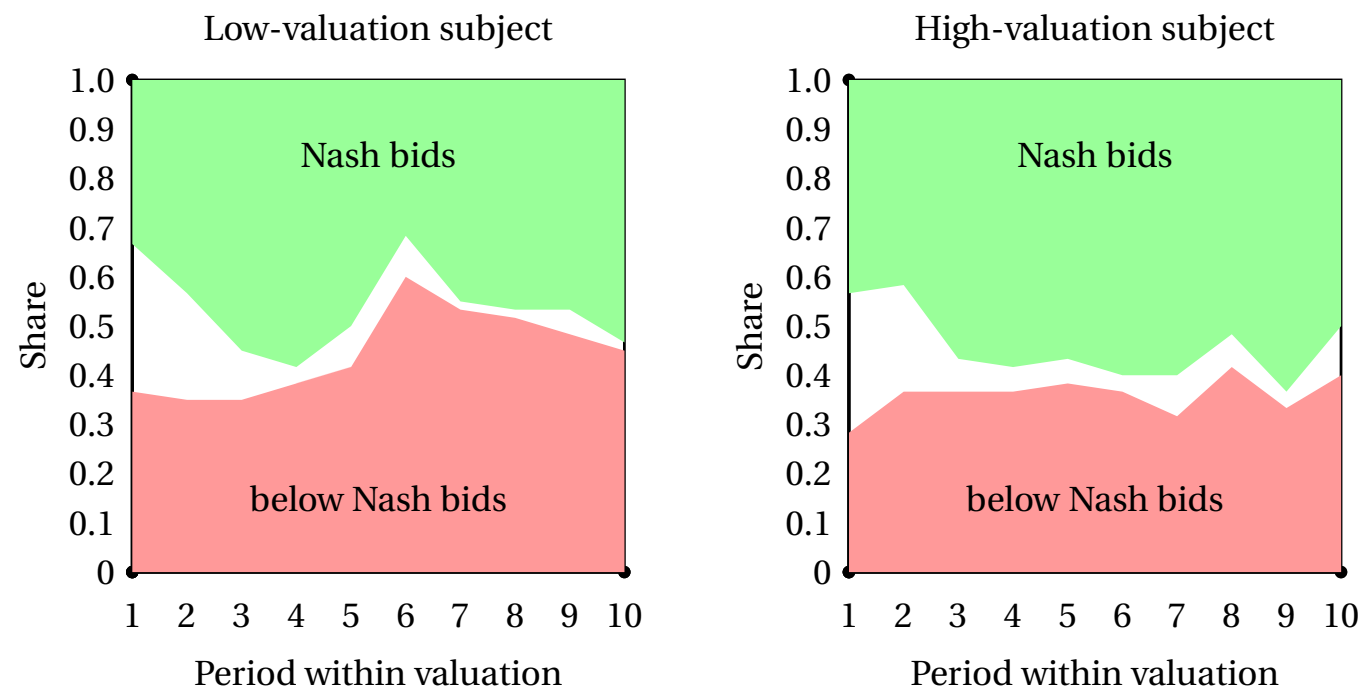

Figure 4: Share of bid types in the winner's-bid auctionover period within valuation by subject value on item B.

non-market division, meaning that independently of the choice of second-mover the outcome would not be a market outcome. In the remaining 88 cases, the divider proposed a division that would have been a market outcome provided the chooser selects the option in line with her self-interest. ${ }^{17}$ Instead the chooser chose the least preferred bundle (i.e., item and transfer payment) — we refer to these situations in which the chooser chose against self-interest as "rejections." Interestingly, while the tendency of dividers to propose non-market divisions abates with experience, the tendency of choosers to reject market proposals persists. Only 7 of the 45 (15.6\%) non-market divisions occur after more than 5 periods of experience within a valuation, but 45 of the 88 (51.1\%) of the choices against self-interest do. Regression results, using valuation fixed effects and the period within valuation variable (not shown) suggest non-market proposals and choices against self interest reduce by $34 \%(p<0.01)$ and $4 \%$ ( $p \approx 0.388$ ), respectively, each successive period within a valuation.

The choices by the second mover against self-interest are hardly random (Fig. 5). They occur most frequently when the divider's proposal is close to the subgame perfect prediction. Moreover, among the proposals that are close to subgame perfect proposals, those made by the high valuation subject are rejected with higher probability than those made by the low valuation subject. To more carefully analyze this behavior, we classify each market division by whether the chooser receives less than a third of the efficiency surplus (divider-favored divisions), between one-third and two-thirds of the efficiency surplus (even divisions), and over two-thirds of the efficiency surplus should she choose the option consistent with self-interest and efficiency (chooser-favored divisions)-this is equivalent to dividing the interval $\left[\underline{x}^{B}, \bar{x}^{B}\right]$ in three subintervals of equal size. The

\footnotetext{
${ }^{17}$ In only one case did the divider propose a non-market division and the chooser chose against selfinterest. That case is only counted as one of the 45 non-market divisions.
} 


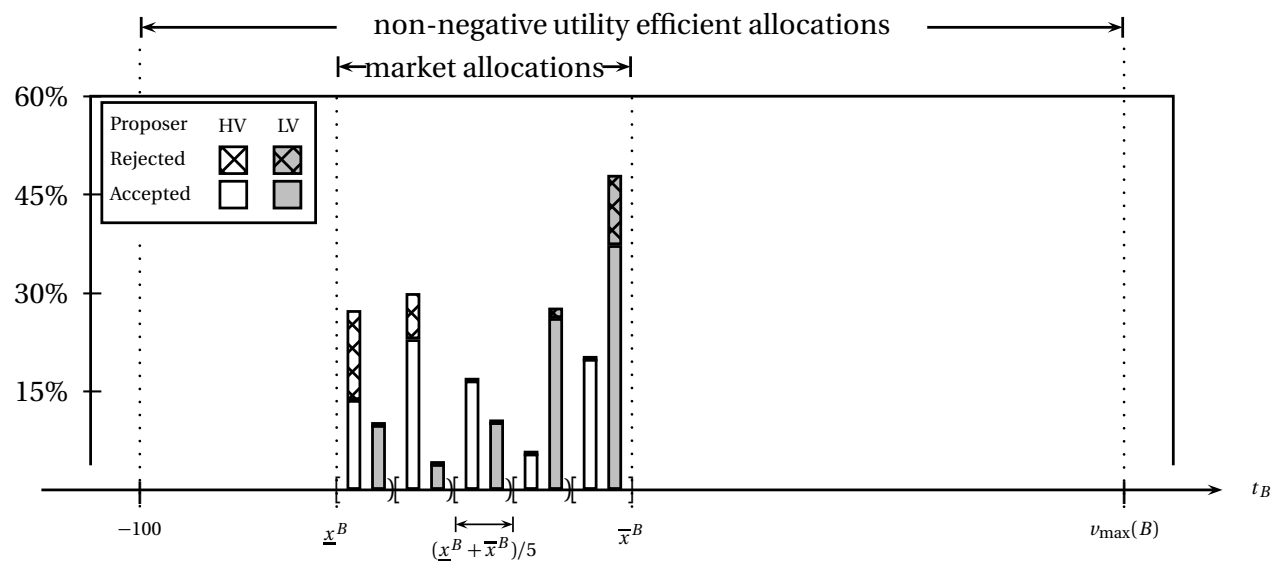

Figure 5: Distribution of market proposals from subjects with the high value (HV) and low value (LV) on item B in divide-and-choose mechanism. Excludes valuation 4, i.e., (160,160). Subjects with the high value on item B propose to take less of the surplus in an efficient allocation than subjects with the low value. The high-value-subject offers are accepted more often. Acceptance means the divider chooses the efficient allocation, one that will give both parties more. See Fig. 1 for the theoretical predictions of the divide-andchoose mechanism.

results are striking: the chooser chose against self-interest in $26.6 \%$ (87 of 327) of divider favored divisions, in $0.4 \%$ ( 1 out of 225 ) of the even divisions and in $0 \%$ ( 0 of 103) of the chooser-favored divisions.

A first observation is that in a proposal that is close to the subgame perfect one, there is little payoff difference between the second mover's choices (Fig. 6 (a)). Indeed, the "rejection cost," i.e., the difference in payoff between the two options for the chooser, is zero for a subgame perfect proposal and increases linearly as the proposal moves away from this subgame perfect prediction (Fig. 6 (b)). For the 88 choices against self-interest of market divisions, the average difference between the two options for the chooser was 4.35 experimental units. For the 567 choices consistent with self-interest of market divisions, the average difference was 15.67 experimental units. It is not just about personal incentives, however. With the divide-and-choose mechanism, low incentives for the chooser to choose self interest are also tied with reciprocity motivations. Recall that the efficiency surplus (ES) is constant for each valuation structure, i.e., the difference between the maximal and minimal valuation for item $B$. Thus, if the rejection cost for a chooser is $r$, the proposer would lose $E S-r$ in case of rejection. Thus, a small difference between two options for the chooser means the divider has proposed to capture much of the efficiency surplus. For example, in valuations 1, 2 and 5, a difference of 4.35 experiment units between the efficient option and the non-efficient option means the divider will get 35.65 experiment units more should the chooser pick her preferred option. ${ }^{18}$

\footnotetext{
${ }^{18}$ In valuation 3 , the efficiency surplus is 80 , meaning such a proposal would give the divider 75.65 should the chooser follow her self interest. In valuation 4 , all outcomes are efficient so the only market division gives equal earnings to each agent.
} 


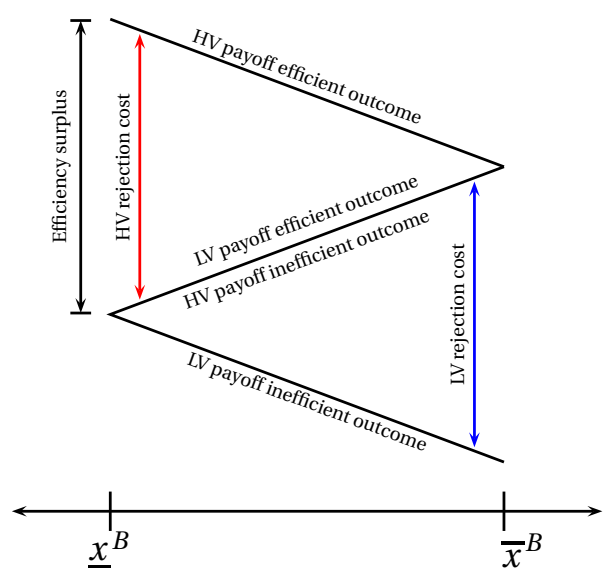

(a)

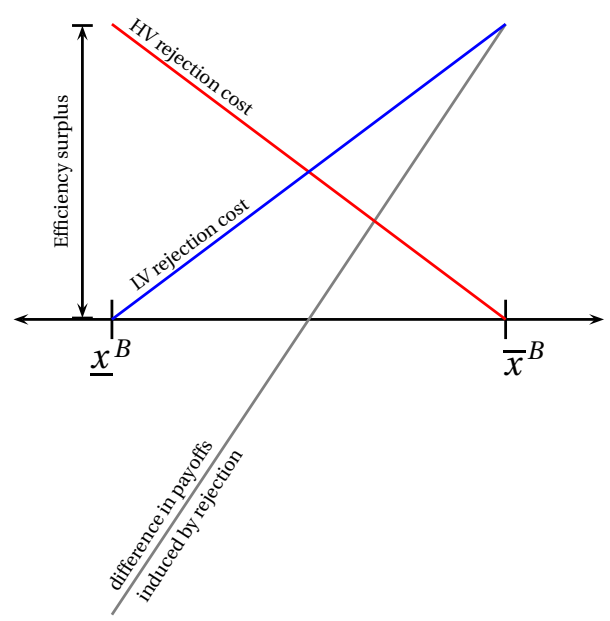

(b)

Figure 6: Incentives in divide-and-choose. (a) Subjects payoffs from divisions in the market range $\left[\underline{x}^{B}, \bar{x}^{B}\right]$. Fo a given proposal $x \in\left[\underline{x}^{B}, \bar{x}^{B}\right]$, the payoff of the high valuation subject in case the proposal is accepted, i.e., the chooser choses the efficient outcome, is given by the line labeled "HV payoff efficient outcome. The other lines represent the respectively labeled payoffs. A subject's rejection cost is given by the difference between her payoff if the efficient outcome is chosen and her payoff if the inefficient outcome is chosen.

Rejection incentives are not symmetric for low and high valuation subjects. Figure 6 (b) shows the difference in payoffs that is induced by a rejection decision. This difference is independent of who is making the rejection decision. On the one hand, if the left extreme of proposal, i.e., $\underline{x}^{B}$, is accepted, the difference in payoffs is the efficiency surplus. If this proposal is rejected, there is equality of payoffs. Thus, rejection of such a proposal decreases inequality of payoffs by an amount equal to the efficiency surplus. This means that the rejection by a low value subject of a subgame perfect proposal reduces inequality of payoffs. On the other hand if the right extreme proposal, i.e., $\bar{x}^{B}$, is accepted, the difference in payoffs is zero. If this proposal is rejected, the difference in payoffs is the efficiency surplus. Thus, rejection of such a proposal increases inequality of payoffs by an amount equal to the efficiency surplus. This means that the rejection by a high value subject of a subgame perfect proposal increases inequality of payoffs.

Our data largely supports that agents take into consideration the inequality of payoffs consequences of their rejection decisions: of the subgame-perfect divisions, the chooser chooses against efficiency $59.0 \%$ of the time (13 of 22) with the low valuation and only $33.3 \%$ (18 of 54 ) with the high-valuation. With proposer-favored divisions (i.e., those at which the chooser receives up to one third of the efficiency surplus), she chooses against efficiency $37.8 \%$ of the time (56 of 148) with the low valuation and only $17.3 \%$ (31 of 179) with the high-valuation.

Table 6 provides regression analysis of the propensity for dividers to choose against self interest using our classification of proposals in three regions (divider-favored, neutral, chooser-favored), the cost in making this choice, and the difference in inequality 


\begin{tabular}{lc}
\hline Dependent variable: & Choice against self interest \\
\hline period within valuation & -0.018 \\
& $(0.065)$ \\
difference in individual payoffs & $-0.270^{* * *}$ \\
& $(0.047)$ \\
difference in inequality & $-0.023^{* * *}$ \\
& $(0.005)$ \\
divider-favored proposal & 0.594 \\
& $(1.233)$ \\
valuation 1 (40-80) & -1.089 \\
& $(1.471)$ \\
valuation 2 (120-160) & -0.696 \\
& $(1.462)$ \\
valuation 3 (40-120) & 0.056 \\
& $(1.592)$ \\
valuation 5 (0-40) & -1.029 \\
& $(1.512)$ \\
Type of regression? & logistic \\
Fixed effects? & First random effects term? \\
Second random effects term? & second-mover (chooser) \\
\hline observations & none \\
log likelihood & $419^{\mathrm{a}}$ \\
\hline * Significant at the $10 \%$ level. & -132.272 \\
*** Significant at the $5 \%$ level. & \\
\end{tabular}

a. Results are restricted to market proposals that are not in valuation 4 or chooser-favored divisions. As choices are equal for market proposals in valuation 4, there is no way a chooser could choose against selfinterest or efficiency. No chooser chose against self-interest with a chooser-favored division, so estimating its logistic term is problematic.

Table 6: Regressions of chooser choice against self-interest (and efficiency) with market divisions in divide-and-choose mechanism, controlling for subject random effects.

induced by rejection. The analysis confirms the statistical significance of what we noted earlier: choosers are more likely to choose against self-interest when the cost of doing so is low; moreover, rejection is more likely when it induces equality.

Result 4. Unlike the ultimatum bargaining mechanism, there is no evidence of the theoretically-predicted, proposer bias in the divide-and-choose mechanism.

Subgame perfect equilibrium predicts that both the divide-and-choose and ultimatum bargaining mechanisms favor the first mover. In our experimental environment, this does not appear to be the case for the divide-and-choose mechanism. Figure 7 shows the excess payment received by the proposer as a percentage of the reponder's payoff, which we refer as proposer bias, over each valuation for the divide-and-choose 


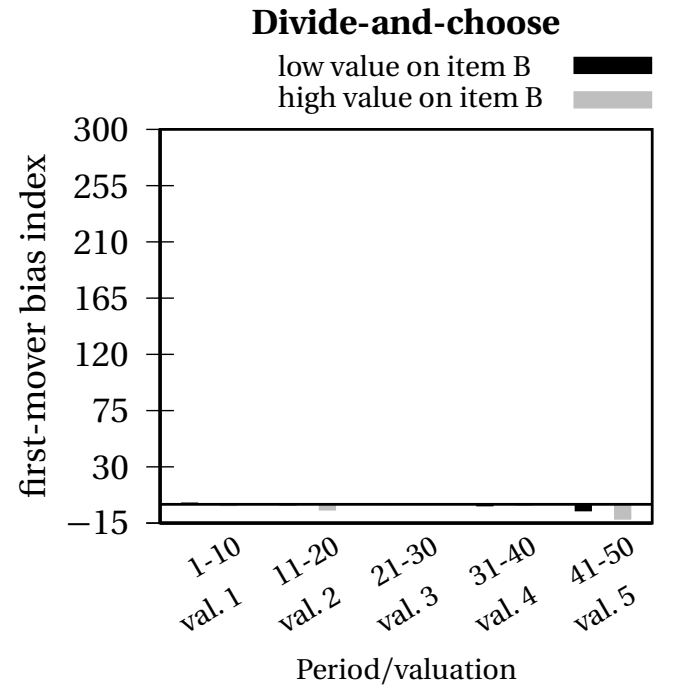

(a)

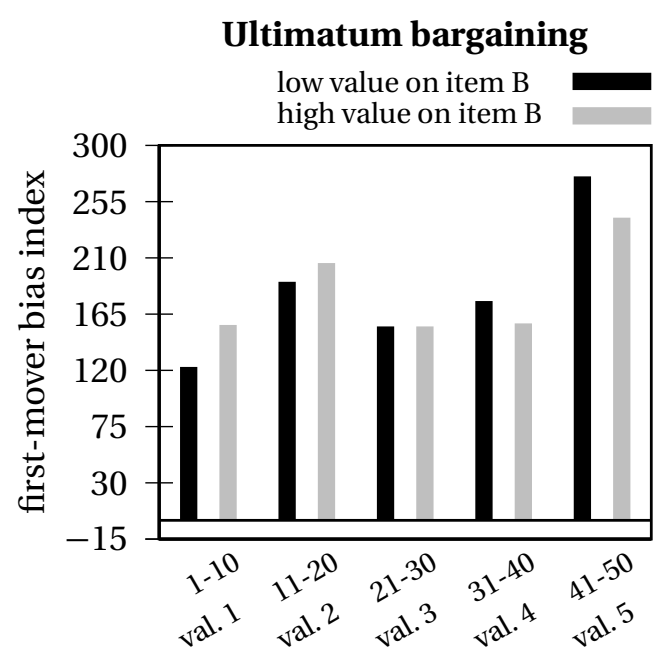

Period/valuation

(b)

Figure 7: First-mover bias in ultimatum bargaining and divide-and-choose separated by whether the proposer had the high or low valuation for item $B$ and by valuation. In each session, over 50 periods, five valuations occurred sequentially for ten periods each. Proposer bias is calculated as (average payoff proposer/average payoff responder)-1. (a, left) In divide-and-choose, no proposer bias is observed. In some valuations, there appears to be evidence of a small chooser bias, but the bias is not of the same magnitude of the bias found in ultimatum bargaining. (b, right) In ultimatum bargaining, regardless of whether the propose had a high or low valuation for item B, the mechanism exhibited a pronounced proposer bias. The proposer on average would earn more than twice as many points as the responder.

and ultimatum bargaining, separated by valuation type. The difference between the figures is striking: regardless of who has the high or low valuation for item B, ultimatum bargaining clearly favors the first mover. If anything, Divide-and-choose appears to provide a much smaller advantage to the second mover.

Table 7 provides the results from six regressions of subject profit and share of combined profit on mechanism with dummy variables for first mover and high value on item B. The regressions use similar fixed and random effects as before (see equations (1) and (2)). The first two regressions show a clear proposer bias in the ultimatum bargaining mechanism: first movers receive on average about 48 points (or 23\%) more earnings than second movers (see row 1, columns 1 and 2). This result is significant at the $1 \%$ level. The results are very different for divide-and-choose, first movers receive on average about 4 points ( $2 \%$ ) less ( $\mathrm{p}<0.05$ and $\mathrm{p}<0.01$, respectively) than second movers (see row 2 , columns 1 and 2 ), revealing if anything a second-mover advantage in divide-andchoose.

Result 3 explains why there is no first-mover advantage in the divide-and-choose mechanism. First-movers do not often propose to capture all the surplus; when they propose to capture more than two-thirds of the surplus, dividers choose against their self-interest and efficiency about $26.6 \%$ of the time. Table 7 also provides regressions on "proposed allocations," that is, how allocations would be decided if the second-mover 
never rejected a proposal. With ultimatum bargaining, the meaning of rejection is clear. As mentioned above, for divide-and-choose we consider a "rejection" to be any time the chooser chose an option that provided the lower payoff for both players. ${ }^{19}$ As expected, these results (third and fourth columns of Table 7) favor the first mover more. First movers propose to take for themselves on average over 60 points (roughly $30 \%$, both $\mathrm{p}<0.001$ ) more than they give to second-movers in their proposals in ultimatum bargaining (row 1, columns 3 and 4). In divide-and-choose first movers take slightly more, but this result is not statistically significant (row 2, columns 3 and 4). ${ }^{20}$

The last two columns (columns 5 and 6) of Table 7 show regressions on subject earnings restricted to proposals that are not rejected. The first-mover advantage falls between the values for overall results (columns 1 and 2) and proposed allocations (columns 3 and 4). Not surprisingly, this indicates that proposals that favor the second-mover more are more likely to be accepted with both mechanisms. Also, the act of rejectioneach player getting 0 in ultimatum bargaining, the chooser taken their lower alternative (and likely causing inefficiency)—reduces the discrepancy between the first and second mover's earnings. This is not surprising for ultimatum bargaining as a rejection assures both players will earn the same amount. In divide-and-choose this implies that these rejections may cause an outcome with higher earnings for the second player, enough to erode any first-mover advantage.

One can relate the absence of proposer advantage in our experimental results and the chooser's advantage predicted for divide-and-choose under incomplete information when agents are risk averse (McAfee, 1992). On the one hand, a proposer in our experiments has some uncertainty about what proposals will be "accepted" by the chooser. On the other hand, with both complete and incomplete information (with independent private values) the chooser faces no uncertainty. Thus, in both cases, the proposer bears all risk in the allocation process and ends up offering on average more than the sub-game perfect prediction under complete information. In our experiments, this effect is aggravated by the fact that the proposer also absorbs a disproportionate share of the efficiency loss caused by the chooser's rejection.

\section{Discussion and concluding remarks}

In laboratory experiments the divide-and-choose mechanism is substantially and significantly superior to the winner's-bid auction when subjects know each other well. Moreover, divide-and-choose does not exhibit a first- or second-mover bias. This is in contrast to laboratory experiments with incomplete information, where divide-and-choose is only weakly superior to the auction (Kittsteiner et al., 2012). It is also in contrast to the

\footnotetext{
${ }^{19}$ In the case of equal payoffs, a rejection is when the second player would choose inefficiency (and giving the first mover less) over efficiency (and giving the first mover more).

${ }^{20}$ if we restrict these regressions to only market proposals (not shown), first movers take 5 points (3\%) more in their proposals $(\mathrm{p}<0.01)$, suggesting off-equilibrium play is responsible for some of the reduction in the first-mover advantage with divide-and-choose.
} 
normative ranking that one can make in terms of procedural justice both under complete and incomplete information (Che and Hendershott, 2008).

Besides providing clear evidence of the ranking between these prominent mechanisms, our results allow us to understand the reasons why behavior in both mechanisms deviates from theoretical predictions. The divide-and-choose mechanism is affected by reciprocity issues and not by bounded rationality. The winner's-bid auction is substantially affected by bounded rationality of the subjects, which produces a self-sustained underbidding. These two results not only further our understanding of these mechanisms, but also point in clear directions in which they can be improved.

First, our results show that agents reject proposals that are perceived as biased towards the proposer in the divide-and-choose mechanism and that the proposals are less likely to being rejected when they induce equality instead of inequality of payoffs. Thus, it is plausible that a mechanism that selects in subgame perfect equilibria an allocation that is a more palatable compromise in the set of market allocations may attain a better performance than divide-and-choose in terms of our two criteria of efficiency and equity. Based on this intuition Nicolò and Velez (2014) have designed an offer-counter-offer mechanism, which allows agents to compromise in a more balanced market allocation which does not depend on the identity of first- and second-movers.

Second, since the winner's-bid auction is substantially affected by the effect that simultaneous play has on bounded rationality subjects, it is plausible that the same effect is extended to all other price rules, i.e., all $\alpha$-auctions described in the introduction. Following this intuition, Brown and Velez (2013) study the performance of these auctions when agents have noisy best responses as in a quantal-response equilibrium model (McKelvey and Palfrey, 1995). The result is that even though all $\alpha$-auctions are strategically equivalent, in particular, have the same equilibrium outcomes, some auctions may perform better than the other in terms of our criteria of efficiency and equity. However, all these auctions are still dominated by the divide-and-choose mechanism. 


\begin{tabular}{|c|c|c|c|c|c|c|}
\hline \multirow{2}{*}{$\begin{array}{l}\text { conditon: } \\
\text { dependent } \\
\text { variable: }\end{array}$} & \multicolumn{2}{|c|}{ overall } & \multicolumn{2}{|c|}{ proposed offers $^{b}$} & \multicolumn{2}{|c|}{ accepted offers $^{b}$} \\
\hline & $\begin{array}{l}\text { profit } \\
\text { (in } \\
\text { points) } \\
(1) \\
\end{array}$ & $\begin{array}{c}\text { share of } \\
\text { total profit } \\
\text { (percent) }^{a} \\
(2) \\
\end{array}$ & $\begin{array}{l}\text { profit } \\
\text { (in } \\
\text { points) } \\
(3) \\
\end{array}$ & $\begin{array}{c}\text { share of } \\
\text { total profit } \\
{\text { (percent) }{ }^{a}}^{(4)} \\
(4)\end{array}$ & $\begin{array}{l}\text { profit } \\
\text { (in } \\
\text { points) } \\
(5) \\
\end{array}$ & $\begin{array}{c}\text { share of } \\
\text { total profit } \\
\text { (percent) }^{a} \\
(6) \\
\end{array}$ \\
\hline $\begin{array}{l}\text { Proposer/first mover in } \\
\text { ultimatum bargaining }\end{array}$ & $\begin{array}{c}47.878^{* * *} \\
(1.740)\end{array}$ & $\begin{array}{l}22.516^{* * *} \\
(0.491)\end{array}$ & $\begin{array}{c}62.956^{* * *} \\
(1.040)\end{array}$ & $\begin{array}{l}29.971^{* * *} \\
(0.493)\end{array}$ & $\begin{array}{l}59.645^{* * *} \\
(1.055)\end{array}$ & $\begin{array}{c}28.094^{* * *} \\
(0.497)\end{array}$ \\
\hline $\begin{array}{l}\text { Divider/first mover in } \\
\text { divide-and-choose }{ }^{c}\end{array}$ & $\begin{array}{c}-3.611^{* *} \\
(1.686)\end{array}$ & $\begin{array}{c}-2.070^{* * *} \\
(0.475)\end{array}$ & $\begin{array}{c}1.243 \\
(1.002)\end{array}$ & $\begin{array}{l}0.921^{*} \\
(0.475)\end{array}$ & $\begin{array}{l}-0.981 \\
(0.987)\end{array}$ & $\begin{array}{l}-0.324 \\
(0.465)\end{array}$ \\
\hline $\begin{array}{l}\text { High value on } B \text { in } \\
\text { ultimatum bargaining }\end{array}$ & $\begin{array}{c}0.278 \\
(1.869)\end{array}$ & $\begin{array}{l}1.034^{* *} \\
(0.526)\end{array}$ & $\begin{array}{l}-0.122 \\
(1.111)\end{array}$ & $\begin{array}{c}1.848 \\
(0.527)\end{array}$ & $\begin{array}{l}-0.367 \\
(1.097)\end{array}$ & $\begin{array}{c}1.621^{* * *} \\
(0.517)\end{array}$ \\
\hline $\begin{array}{l}\text { High value on B in } \\
\text { divide-and-choose }\end{array}$ & $\begin{array}{c}16.570^{* * *} \\
(1.808)\end{array}$ & $\begin{array}{c}9.618^{* * *} \\
(0.510)\end{array}$ & $\begin{array}{c}18.346^{* * *} \\
(1.074)\end{array}$ & $\begin{array}{c}9.465^{* * *} \\
(0.510)\end{array}$ & $\begin{array}{c}16.933^{* * *} \\
(1.059)\end{array}$ & $\begin{array}{c}8.445^{* * *} \\
(0.499)\end{array}$ \\
\hline Ultimatum bargaining $^{d}$ & $\begin{array}{c}-33.007^{* * *} \\
(3.000)\end{array}$ & $\begin{array}{c}-8.910^{* * *} \\
(0.954)\end{array}$ & $\begin{array}{c}-24.957^{* * *} \\
(1.164)\end{array}$ & $\begin{array}{c}-11.478^{* * *} \\
(0.552)\end{array}$ & $\begin{array}{c}-24.850^{* * *} \\
(2.406)\end{array}$ & $\begin{array}{c}-11.643^{* * *} \\
(1.135)\end{array}$ \\
\hline Type of regression? & linear & linear & linear & linear & linear & linear \\
\hline $\begin{array}{l}\text { Fixed effects? } \\
\text { First random } \\
\text { effects term? }\end{array}$ & $\begin{array}{c}\text { each period } \\
\text { subject }\end{array}$ & $\begin{array}{c}\text { each period } \\
\text { subject }\end{array}$ & $\begin{array}{l}\text { each period } \\
\text { subject who is } \\
\text { first mover }\end{array}$ & $\begin{array}{l}\text { each period } \\
\text { subject who is } \\
\text { first mover }\end{array}$ & $\begin{array}{c}\text { each period } \\
\text { subject }\end{array}$ & $\begin{array}{c}\text { each period } \\
\text { subject }\end{array}$ \\
\hline $\begin{array}{l}\text { Second random } \\
\text { effects term? }\end{array}$ & $\begin{array}{c}\text { player paired } \\
\text { with subject }\end{array}$ & $\begin{array}{l}\text { player paired } \\
\text { with subject }\end{array}$ & $\mathrm{n} / \mathrm{a}$ & $\mathrm{n} / \mathrm{a}$ & $\begin{array}{c}\text { player paired } \\
\text { with subject }\end{array}$ & $\begin{array}{c}\text { player paired } \\
\text { with subject }\end{array}$ \\
\hline observations & 2700 & 2700 & 2700 & 2700 & 2322 & 2322 \\
\hline log likelihood & -18710.021 & -14746.764 & -11742.358 & -9876.116 & -9918.017 & -8170.774 \\
\hline
\end{tabular}

a. In divide-and-choose, a rejection is the divider choosing the option that gives him less points, or in a case of equal points, the inefficient outcome. Thus a divider's proposal is what would be implemented given the chooser does not reject.

b. A rejection in ultimatum bargaining leads to earnings of 0 for each player. We consider this to be a $50 \%$ share for each player.

c. This value represents the relative gain over a low valuation/second mover.

d. This value represents the predicted value for a low valuation second mover, relative to period fixed effects.

Table 7: Regressions of subject earnings on mechanism, valuation, first mover, and item B value, controlling for period fixed effects and subject random effects. 


\section{References}

Abdulkadiroğlu, A., Sönmez, T., Ünver, M. U., 06 2004. Room assignment-rent division: A market approach. Soc Choice Welfare 22 (3), 515-538.

Alkan, A., Demange, G., Gale, D., 1991. Fair allocation of indivisible goods and criteria of justice. Econometrica 59, 1023-1039.

Andersson, T., Ehlers, L., Svensson, L.-G., 2010. Budget-balance, fairness and minimal manipulability. Cahiers de recherche 18-2010, Centre interuniversitaire de recherche en économie quantitative, CIREQ.

Andersson, T., Ehlers, L., Svensson, L.-G., 2012. (minimally) espsilon-incentive compatible competitive equilibria in economies with indivisibilities. Cahiers de recherche 042012, Centre interuniversitaire de recherche en économie quantitative, CIREQ.

Āzacis, H., 2008. Double implementation in a market for indivisible goods with a price constraint. Games Econ Behavior 62, 140-154.

Beviá, C., 2010. Manipulation games in economies with indivisible goods. International Journal of Game Theory 39 (1), 209-222.

Brams, S., Taylor, A., 1996. Fair Division : From Cake-Cutting to Dispute Resolution. Cambridge University Press.

Brown, A. L., Velez, R. A., 2013. Optimal competitive auctions, Mimeo, Texas A\&M University.

Charness, G., Rabin, M., 2002. Understanding social preferences with simple tests. Quarterly journal of Economics, 817-869.

Che, Y.-K., Hendershott, T., June 2008. How to divide the possession of a football? Econ Letters 99 (3), 561-565.

Cooper, D. J., Fang, H., 2008. Understanding overbidding in second price auctions: An experimental study. The Economic Journal 118 (532), 1572-1595.

Costa-Gomes, M. A., Weizsäcker, G., 2008. Stated beliefs and play in normal-form games. The Review of Economic Studies 75 (3), 729-762.

Cramton, P., Gibbons, R., Klemperer, P., 1987. Dissolving a partnership efficiently. Econometrica 55 (3), pp. 615-632.

Crawford, V. P., 1977. A game of fair division. The Review of Economic Studies 44 (2), pp. 235-247.

Crawford, V. P., Heller, W. P., 1979. Fair division with indivisible commodities. Journal of Economic Theory 21 (1), 10-27. 
de Frutos, M.-A., Kittsteiner, T., 2008. Efficient partnership dissolution under buy-sell clauses. The RAND Journal of Economics 39 (1), 184-198.

Dupuis-Roy, N., Gosselin, F., 2009. An empirical evaluation of fair-division algorithms. In: Love, B. C., McRae, K., Sloutsky, V. M. (Eds.), Proceedings of the 30th Annual Conference of the Cognitive Science Society. Cognitive Science Society, Amsterdam, NL, pp. 2681-2686.

Dupuis-Roy, N., Gosselin, F., 2011. The simpler, the better: a new challenge for fairdivision theory. In: Love, B. C., McRae, K., Sloutsky, V. M. (Eds.), Proceedings of the 32th Annual Conference of the Cognitive Science Society. Cognitive Science Society, Amsterdam, NL, pp. 3229-3234.

Fair Outcomes Inc., 2007-2013. Fair buy-sell. URL http://www. fairoutcomes . com/fb.html

Fischbacher, U., 2007. Z-tree: Zurich toolbox for ready-made economic experiments. Experimental Economics 10 (2), 171-178.

Foley, D., 1967. Resource allocation and the public sector. Yale Economic Essays 7, 45-98.

Fudenberg, D., Levine, D., 1983. Subgame-perfect equilibria of finite- and infinitehorizon games. J Econ Theory 31 (2), $251-268$.

Fujinaka, Y., Wakayama, T., 2012. Maximal manipulation in fair allocation, Mimeo.

Greiner, B., 2004. The online recruitment system orsee 2.0 - a guide for the organization of experiments in economics. University of Cologne Discussion Paper (www.orsee.org).

Guth, W., Schmittberger, R., Schwarze, B., 1982. An experimental analysis of ultimatum bargaining. Journal of Economic Behavior \& Organization 3 (4), 367 - 388.

Herreiner, D. K., Puppe, C. D., 2009. Envy freeness in experimental fair division problems. Theory and Decision 67, 65-100.

John, O. P., Naumann, L. P., Soto, C. J., 2008. Paradigm shift to the integrative big-five trait taxonomy: History, measurement, and conceptual issues. In: John, O. P., Robins, R. W., Pervin, L. A. (Eds.), Handbook of Personality: Theory and Research. Guilford Press, New York, NY, pp. 114-158.

Kittsteiner, T., Ockenfels, A., Trhal, N., 2012. Partnership dissolution mechanisms in the laboratory. Econ Letters 117 (2), 394 - 396.

McAfee, P. R., 1992. Amicable divorce: Dissolving a partnership with simple mechanisms. Journal of Economic Theory 56 (2), 266-293. 
McKelvey, R. D., Palfrey, T. R., 1995. Quantal response equilibria for normal form games. Games and Economic Behavior 10 (1), 6-38.

Moulin, H., 2006. Social choice. In: Weingast, B. R., Wittman, D. A. (Eds.), Handbook of Political Economy. Oxford University Press, pp. 373-389.

Nicolò, A., Velez, R., 2014. Divide and compromise, Mimeo.

Radner, R., 1980. Collusive behavior in noncooperative epsilon-equilibria of oligopolies with long but finite lives. J Econ Theory 22 (2), 136 - 154.

Roider, A., Schmitz, P. W., 2012. Auctions with anticipated emotions: Overbidding, underbidding, and optimal reserve prices. The Scandinavian Journal of Economics 114 (3), 808-830.

Schneider, G., Krämer, U. S., 2004. The limitations of fair division: An experimental evaluation of three procedures. Journal of Conflict Resolution 48 (4), 506-524.

Spliddit, 2014.

URL http: //www.spliddit.org/

Splitwise Inc., 2014. Split expenses with friends: Splitwise.

URL http://splitwise.com

Svensson, L.-G., 1983. Large indivisibles: an analysis with respect to price equilibrium and fairness. Econometrica 51, 939-954.

Tadenuma, K., Thomson, W., May 1995. Games of fair division. Games and Economic Behavior 9 (2), 191-204.

Thomson, W., 2010. Fair allocation rules. In: Arrow, K., Sen, A., Suzumura, K. (Eds.), Handbook of Social Choice and Welfare. Vol. 2. North-Holland, Amsterdam, New York, Ch. 21.

Varian, H. R., 1976. Two problems in the theory of fairness 5 (3-4), 249-260.

Velez, R. A., 2011. Are incentives against economic justice? J Econ Theory 146, 326-345.

Velez, R. A., 2013. Sincere and sophisticated players in the envy-free allocation problem, Mimeo, Texas A\&M University. 